

\title{
Study demonstrates ozone uptake by SJV crops
}

\section{David A. Grantz \\ ․ J. Ian MacPherson}

James Pederson

The Callfornla Ozone Deposition Experiment, using Instruments mounted In an alrplane and on the ground, shows that agricultural land In the San Joaquin Valley removes large amounts of ozone from valley alr. The most actlve pathway Is uptake through stomata in plant leaves, the process leading to crop yleld losses. Other pathways, Including ozone destruction on leaf, stem and soil surfaces, are slower but very Important on a valley-w/de basis. Ozone deposition to crops may have a slgnificant Impact on alr quality, and should be consldered when farmland is converted to urban uses that contrlbute more to ozone production and less to ozone removal.
Air pollution is a serious health hazard and is well known to reduce agricultural yields. In the San Joaquin Valley (SJV), unlike some other areas, these biological effects are almost entirely due to ozone $\left(\mathrm{O}_{3}\right)$. Ozone forms when an activated atom of oxygen $(\mathrm{O})$ combines with a molecule of oxygen $\left(\mathrm{O}_{2}\right)$ during a complex cycle of reactions involving hydrocarbons, nitrogen oxides and sunlight. This ozone in the troposphere near the ground is completely separate from the much higher ozone levels in the stratosphere that protect the earth against ultraviolet radiation.

Under current levels of ozone, yields of crop plants ranging from trees and grapevines to field crops and pasture grasses are reduced. Some yields are reduced by $20 \%$ or more. Indeed, ozone costs SJV farmers hundreds of millions of dollars each year and the state economy much more. The rising population in the SJV, with its associated urban energy consump-
A heavily instrumented Twin Otter research aircraft was used during the CODE experiment to measure ozone deposition to an irrigated vineyard in the San Joaquin Valley.

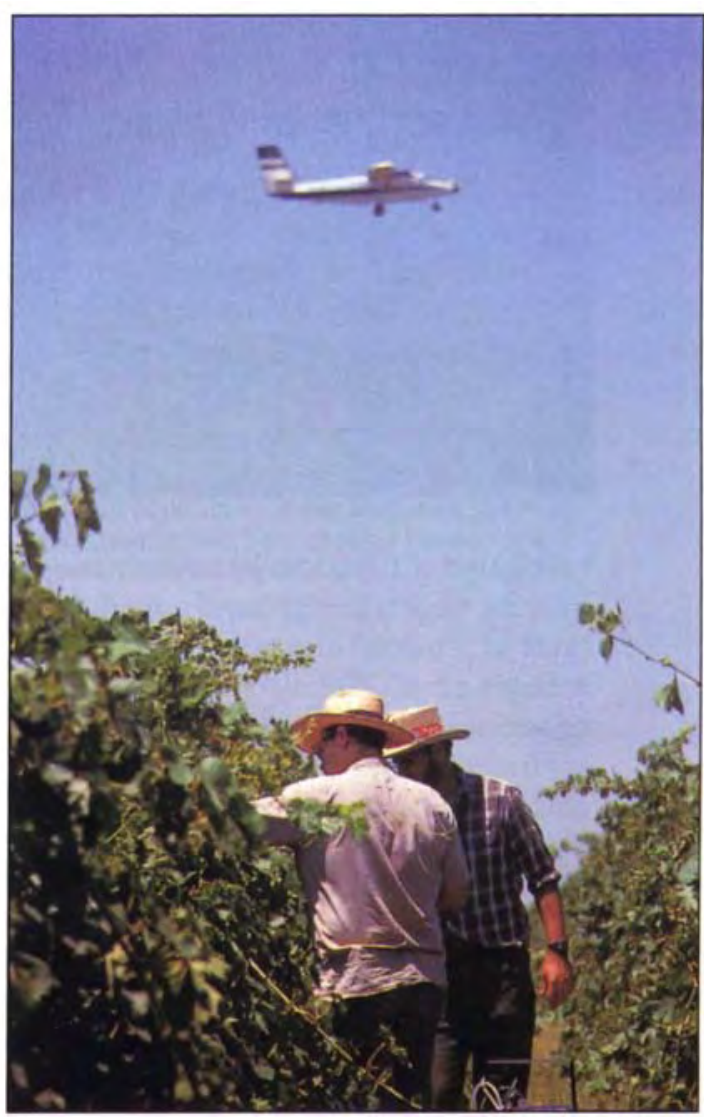

Measurements of ozone deposition and greenness were obtained by aircraft directly over the heads of researchers obtaining measurements of photosynthesis and stomatal conductance in an irrigated vineyard.

tion and vehicle miles traveled, suggests even higher ozone levels in the future. Some farm operations - those involving pumps, land cultivation and transport of commodities to market also generate precursors of ozone.

To model air pollution episodes and identify effective pollution-control strategies, and thereby provide data to agriculturists to support estimates of potential crop losses, a cooperative research project known as the San Joaquin Valley Air Quality Study was conducted. This study will ultimately lead to a comprehensive computer model of interacting sources and sinks for ozone.

One component of this study was the California Ozone Deposition Experiment of 1991 (CODE). CODE in- 


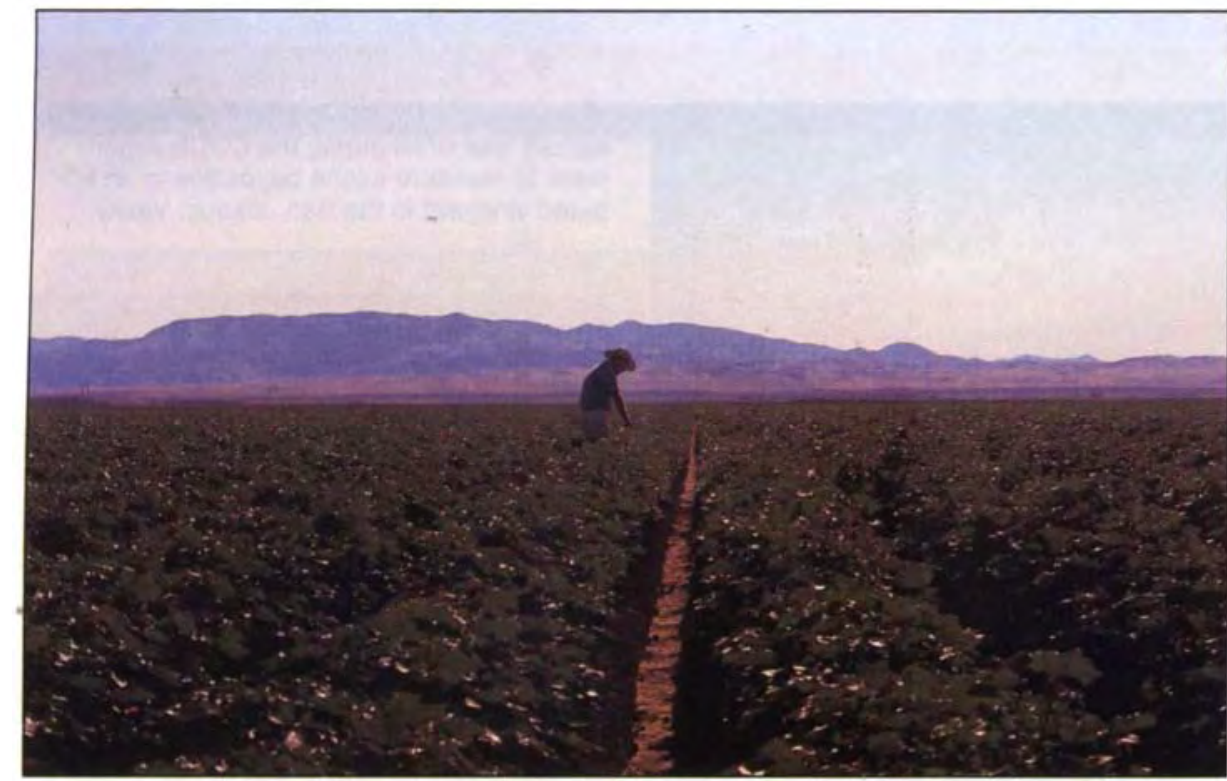

vestigated differences between contrasting vegetative ground covers in rates of removal of ozone from the valley's air. CODE also explored the relationship between plant physiological function and this ozone removal, using fluxes of water vapor from plant transpiration and carbon dioxide from photosynthesis as well-characterized measures of plant metabolic activity.

Removal of air pollutants by accumulation or destruction at the ground surface, in the absence of rain or snowfall, is known as dry deposition. The strength, or activity, of a specific ground cover in removing ozone is described by a dry deposition velocity, calculated as the ratio of removal rate a: the ground surface to the ozone concentration in the air.

\section{The CODE Study}

CODE involved a number of research groups from different institu- tions. Instruments were mounted on micrometeorological towers for intensive studies at specific cotton, vineyard and unirrigated rangeland sites. Larger-scale measurements were obtained using instruments mounted in a Twin Otter research aircraft operated by the National Research Council of Canada. The aircraft made repeated overflights at 100 feet above the ground of specific areas of the valley, including those in which the towers were located. The aircraft measurements and supporting ground-based physiological measurements are presented here.

The Twin Otter was outfitted with a large array of sensors, as described in the report "NRC Twin Otter operations in the 1991 California Ozone Deposition Experiment" (MacPherson, 1992), prepared by the Institute for Aerospace Research of the National Research Council of Canada. Rapid-

TABLE 1. Acreage, ozone uptake characteristics, and estimated total ozone uptake of selected San Joaquin Valley crops

\begin{tabular}{lccr}
\hline \hline Crop type & $\begin{array}{c}\text { Deposition } \\
\text { velocity }\end{array}$ & $\begin{array}{c}\text { Number } \\
\text { of acres* }\end{array}$ & $\begin{array}{c}\text { Ozone } \\
\text { depositiont }\end{array}$ \\
\hline Cotton & in./sec & 1,000 & $1,000 \mathrm{lb} /$ day \\
Corn & 0.31 & 1,111 & 325 \\
Grapes & 0.30 & 205 & 59 \\
Orchards $\neq$ & 0.25 & 544 & 128 \\
Rangeland & 0.24 & 301 & 67 \\
\hline
\end{tabular}

-Total for Fresno, Kings, Kern, Madera, Merced, Stanislaus, Tulare, Tuolumne, and Mariposa counties. †Assuming 12-hour day and approximately $45 \mathrm{ppb}$ ambient ozone as observed above cotton in western Fresno County. Deposition reflects downward flux of ozone at the measurement height of the aircraft, assumed to be similar to the flux at the ground surface.

¥Largely almonds and figs.

The eddy correlation technique requires large ground areas with a similar type of surface cover, such as the large cotton fields in the western San Joaquin Valley.

response instruments were used to sample concentrations of ozone, carbon dioxide and water vapor, as well as temperature and three-dimensional wind velocity, at 16 times per second. This rapid sampling allowed calculation of the fluxes of water vapor from the vegetated and unvegetated ground surfaces (evapotranspiration) and of the fluxes of ozone (dry deposition) and carbon dioxide (photosynthesis) to these ground surfaces. The calculation technique known as eddy correlation was used to relate gas concentrations with individual up- and down-drafts (eddies) to calculate the transport of each of the trace gases of interest at the height of the aircraft. It is assumed that these fluxes are similar to fluxes occurring throughout the air column below the aircraft and at the ground surface. In fact, during CODE the agreement between aircraft and tower estimates of gas fluxes was quite good at each of the intensive sites. A deposition velocity was calculated for each segment of the flight path. Using onboard video imaging and land-use maps, these deposition velocities were assigned to specific ground covers.

In addition to ozone and carbon dioxide transfer properties, the aircraft used measurements of reflected and emitted radiation in different bands of the electromagnetic spectrum to determine a greenness index and a temperature over each type of vegetation.

The aircraft measurements were supplemented with ground-based determinations of stomatal conductance and photosynthetic activity of individual leaves, performed with a transient gas exchange system (LiCor 6200 , LiCor, Inc.), during the same time period and often simultaneously with aircraft overflights. Stomatal conductance is a measure of the opening of pores in the leaves that allow water vapor to escape and through which carbon dioxide enters for photosynthesis. Ozone is also believed to enter 
leaves through the stomata. Groundbased instruments also included leaf wetness sensors and infrared thermometers to sample soil and leaf temperatures.

\section{High ozone uptake by cotton}

Irrigated cotton plants exhibited high activity for uptake of ozone, as indicated by the large daytime deposition velocity (table 1 , column 2 ). This high activity, combined with the large acreages planted to irrigated cotton in the San Joaquin Valley (column 3), resulted in large daily removals of ozone from valley air (column 4). Corn was about as active in ozone uptake as cotton, per unit ground area; but with much less acreage, it did not remove nearly as much ozone from the air ba$\sin$. Grapes and orchard trees were somewhat less active, as expected from the typically lower transpiration and photosynthetic rates of woody perennial plants. Uptake by other irrigated crops grown in the San Joaquin Valley is likely to fall within the range of activities between corn and orchards.

Of special interest is the unirrigated rangeland pasture (table 1 ). The grasses and other plants in these areas were largely dead or dormant during the summer, with little stomatal conductance or wet interior surfaces within the leaves on which ozone could react. As a result, this ground surface cover had a very low ozone deposition velocity on a unit ground area basis. Yet ozone decomposition did occur at a low rate as reactive ozone molecules collided with the relatively inert external surfaces of soil, plant residues and other materials on the ground. The very large acreage devoted to this land use in the San Joaquin Valley resulted in a significant calculated uptake of ozone from the air basin, even greater than that by cotton.

Where does the ozone go? The most active ozone fluxes on a ground area basis were over non-dormant, physiologically active vegetation with high rates of transpiration and photosynthesis. Previous experiments involving laboratory fumigation of individual leaves suggest that most of this ozone, lost from the lower atmosphere, was taken up by leaves through the stomata and destroyed on contact with the living tissues within. Destruction of ozone involves transfer of its strong oxidizing power to biochemical plant constituents, with resulting physiological damage. It is this component of ozone deposition (uptake) that leads to most crop yield losses. Much smaller deposition to soil, stem and leaf surfaces is not likely to cause as much damage, although ozone destruction of leaf cuticles has been observed. Larger localized fluxes that have been observed over cities, highways and even bare fields probably represent chemical reactions in the air between ozone and gaseous emissions such as nitric oxide.

The role of stomatal uptake over physiologically active vegetated ground surfaces can be shown in several ways. The magnitude of day-night changes in deposition was closely tied to the metabolic activity of the underlying vegetation type. Most of the uptake occurred during daylight hours when stomata in plant leaves were open, and declined at night when stomata were closed.

In cotton (fig. 1) and in grapes (not shown), ozone deposition was closely related to stomatal conductance. The differences in deposition velocity between different crops (table 1) are due largely to differences in stomatal conductance. For example, cotton is a very physiologically active plant, with large stomatal conductance and rapid exchange of water vapor, carbon dioxide and ozone. Vineyards and orchards, with typically lower stomatal conductances, had lower deposition velocities than cotton. Dormant rangeland, with minimal stomatal conductance, had very low ozone uptake activity (table 1). The modest diurnal trend in ozone deposition over areas such as dormant grassland probably reflects changes in mixing of the atmosphere due to solar heating.

Deposition velocity over a range of plant types was closely related to the downward flux of carbon dioxide, as determined from the aircraft measurements (fig. 2). The sink for this carbon dioxide is photosynthesis, the conver-

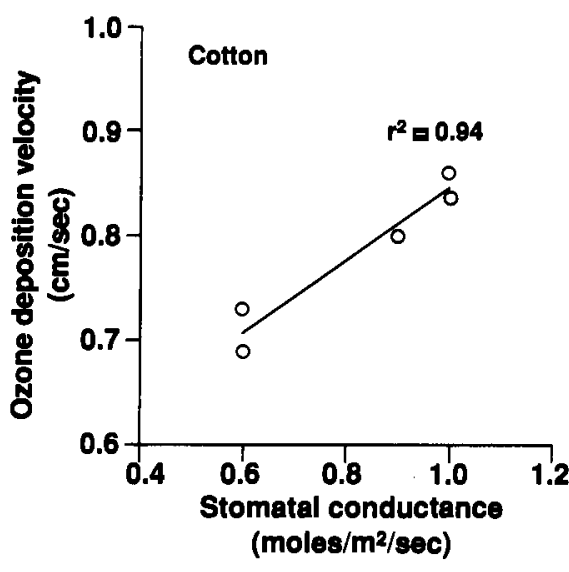

Fig. 1. Ozone deposition velocity (uptake activity) determined by aircraft over a large irrigated cotton field was closely related to the stomatal conductance per leat area (plant activity) determined from ground-based measurements in the same field.

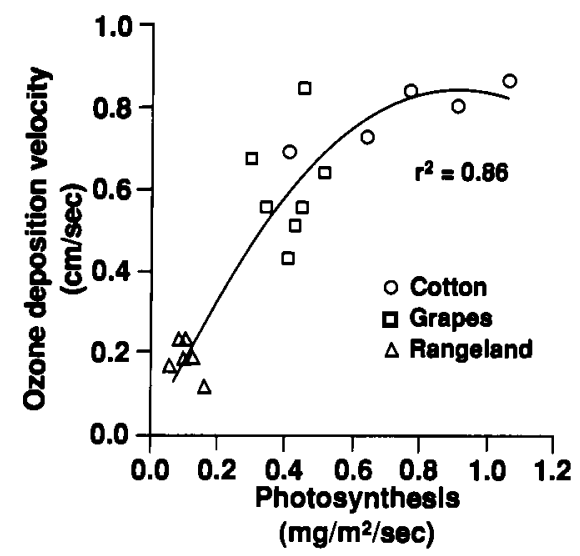

Fig. 2. Ozone deposition velocity (uptake activity) determined by aircraft over irrigated cotton and grapes and unirrigated grassland pasture was closely related to the carbon dioxide flux per unit ground area determined by the aircraft, a measure of photosynthesis (plant activity).

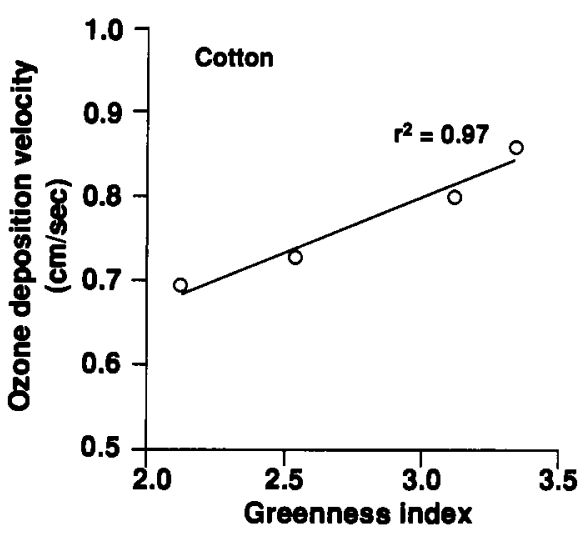

Fig. 3. Ozone deposition velocity determined by aircraft was closely related to the greenness of the plant cover determined using remote sensing from the aircraft. 


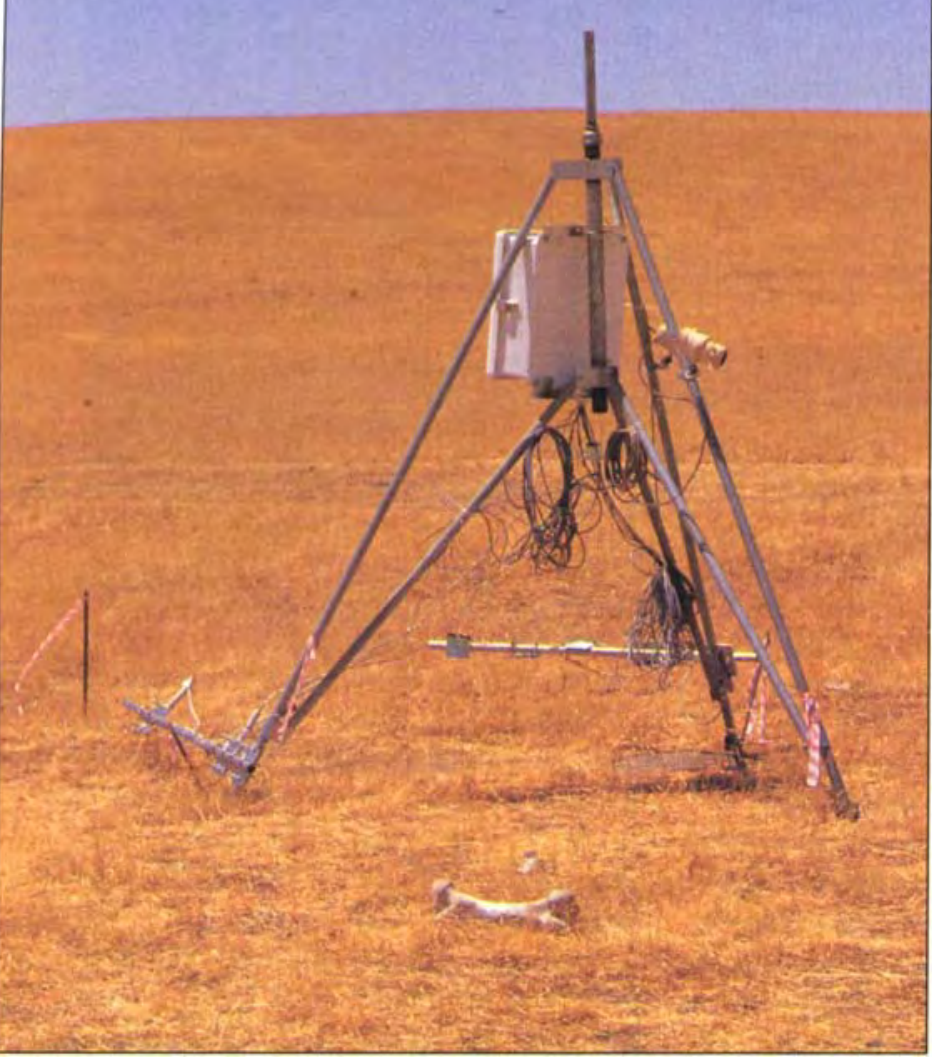

A small instrument tripod in the unirrigated grassland pasture allowed continuous measurement of surface temperature and wetness.

sion of carbon dioxide to sugar within the leaves, a measure of plant activity. When plants were metabolically active, ozone uptake was large. When plants were inactive, ozone uptake was greatly reduced.

Another way of relating ozone deposition to the biological activity of the underlying crop cover is to use airborne remote sensing techniques to infer the amount and activity of living plant material on the ground. A greenness index (Vegetation Greenness Indicator, Skye Industries) was derived from the ratio of infrared to red radiation detected by radiometers on the aircraft. Deposition velocity was closely related to greenness as both increased with age and ground cover of the cotton crop (fig. 3). A similar relationship (not shown) was observed over a range of ground covers from dry rangeland (low greenness and low deposition velocity), through orchards and grapes (moderate greenness and activity), to cotton and corn (high greenness and high deposition velocity).

All evidence indicates that the most active ozone loss from the lower atmosphere during these aircraft overflights was due to uptake by leaves of actively transpiring and photosynthesizing plants. This is suggested by the correlations between photosynthesis or stomatal conductance and ozone deposition, presented above, whether the correlations are obtained across different plant species, through time as plants mature, or over day/night cycles of physiological activity. It is further supported by the correlation between remotely sensed greenness of the plant cover and ozone deposition. All of these field observations are consistent with laboratory evidence that the stomatal pathway dominates ozone deposition to active leaves.

Effects on air quality. The role of dry deposition to agricultural crops, native vegetation and other ground surfaces was evaluated during CODE as a potential input to the computer model of regional air quality being developed through the San Joaquin Valley Air Quality Study. Preliminary model analyses during planning of CODE (Hubbe, Pederson and Hansen. 84th Annual Meeting of the Air and Waste Management Association, 1991.) suggested that dry deposition could provide a significant sink for ozone, substantially altering the distribution and concentrations of ozone in the San Joaquin Valley. The relative importance of uptake by crops versus other ground surfaces remains to be fully determined.

\section{Future air quality}

There are numerous urban pressures on agriculture in California, largely attributed to rapidly rising populations in areas such as the San Joaquin Valley. Growers must contend with loss of agricultural lands to development, competition for uncertain water supplies and reduced yields due to ozone exposure. The value of farmland as a food source and as an aesthetic resource is well known. The CODE data described here suggest that maintaining air quality may be an additional value of preserving crop cover on agricultural lands. Although reducing emissions of precursors is the most effective way to prevent ozone formation, living plants provide a strong sink for ozone removal from the atmosphere. This study gives us yet another reason to balance needs for growth and development with long-term needs for healthy supplies of food and air.

D. A. Grantz is Extension Air Quality Specialist, Department of Botany and Plant Sciences, and Plant Physiologist, Statewide Air Pollution Research Center, UC Riverside, located at the Kearney Agricultural Center, Parlier; J. I.

MacPherson is Program Manager, Atmospheric Geoscience at the Institute for Aerospace Research, National Research Council of Canada, Ottawa; W.J. Massman is Meteorologist, U.S. Forest Service, Fort Collins, Colorado; and J. Pederson is Atmospheric Scientist, Califormia Air Resources Board, Sacramento.

The authors gratefully acknowledge the San Joaquin Valley Air Pollution Study Agency, the National Research Council of Canada, and UC Cooperative Extension for financial support, and M. K. Scaff for assistance in preparation of the manuscript. The statements and conclusions expressed in this publication are those of the authors, and do not necessarily represent the views or the policies of the California Air Resources Board, the San Joaquin Valley Air Quality Study Policy Committee, or any other organizations, their employees or members.

For more information about this project, please contact David Grantz at (209) 891-2500. 